\title{
Scholarly communication and
} matters of trust and authority: A comparative analysis of Malaysian and Chinese researchers

\author{
A. Abrizah ${ }^{1,3}$, Jie $\mathbf{X u}^{2}$ and David Nicholas ${ }^{3}$ \\ ${ }^{1}$ Department of Library \& Information Science, \\ Faculty of Computer Science \& Information Technology \\ University of Malaya, Kuala Lumpur, MALAYSIA \\ ${ }^{2}$ School of Information Management, Wuhan University, CHINA \\ ${ }^{3}$ CIBER Research Ltd., Newbury, Berkshire, UNITED KINGDOM \\ e-mail: abrizah@um.edu.my (corresponding author); \\ xuj@whu.edu.cn (corresponding author); Dave.Nicholas@ciber-research.eu
}

\begin{abstract}
The study is a follow up of CIBER's exploratory research on Trust and Authority in Scholarly Communications conducted in 2012-2013, investigating Malaysia, a country currently on the 'periphery' of the scholarly endeavor and comparing with China, now stands $2^{\text {nd }}$ globally to the USA in terms of scientific output. Over 500 Malaysian researchers were surveyed about the opinions on trustworthiness when it came to their scholarly use/reading, citing and publishing. A high proportion of respondents were affiliated to research-intensive universities, with the early career researchers and physical sciences being very well-represented. The attitudes and behaviours of Malaysian researchers were compared with an earlier study of more than 660 Chinese, the methods and questions of which were replicated from the CIBER study. Results indicate that the measures of establishing trust and authority in scholarly communication do not seem to have differed profoundly in Malaysia and China.
\end{abstract}

Keywords: Publication behavior; Citation behaviour; Scholarly communication; Trust and authority; Social media; Open access publishing.

\section{INTRODUCTION}

Borgman (2007) argues that in the context of the modern research enterprise, scholarly communication achieves three major functions: “(a) it legitimizes scholarly work; (b) it disseminates that work to an audience (or to multiple audiences); and (c) it provides access, preservation, and curation" (p.74). Trust and authority has become embedded within the system of scholarly communication and helps explain why traditional indicators remain robust even while sources and channels of scholarly communication are rapidly evolving in the digital environment. Trust and authority matters everywhere, but they are the "very watchwords of scholarly communication" (Nicholas et al. 2015a), a system designed to deliver quality assurance. There have been several studies about trustworthiness and scholarly communications in the digital age, reporting on the findings of an international project funded by the Alfred P. Sloan Foundation, which focused largely, but not exclusively, on English language publications and US/UK researchers (Tenopir et al. 2013), as well as differences in scholarly behaviour in respect to the age, nationality, institution, gender and discipline of the researcher (Jamali et al. 2014; Nicholas et al. 2015a; Nicholas et al. 2015b). 
The inequalities in the usage, citation and publication of research from countries on the outskirts of international scholarship and the move to digital scholarship, amplified by the use of social media and Open Access, may have served to break down the social and cultural barriers that prevent academics from peripheral countries to take their rightful place in the international research community. The literature indicates that most of the world's scholarly research activity is concentrated in a few scientifically and technologically advanced countries, where spending on research and development is the highest (National Science Board 2016). The scientific world is divided into centres and peripheries, a demarcation that is typically seen as corresponding to the divide between the affluent, industrialised states of the northern hemisphere and the less well-off and technologically less advanced nations of the south (Abrizah et al. 2015). Nonetheless, for a variety of structural and cultural reasons, the 'newly industrialised' countries (NIC), such as China that was once on the periphery of world science, has currently explosive scientific growth and continues to reshape the international research base. By the measure of annual output, China surpassed Japan, the UK and Germany in 2006 and stands second only to the USA (Adams, King and Ma 2009). A 2020 target to rank among the world's top-five countries by aggregated scientific paper citations was set by Chinese government planners in 2006-a target that was achieved in 2012 (Bound et al. 2013). Other countries currently on the 'periphery' of the scholarly endeavor such as Malaysia has also improved in terms of scientific output. The research capacity and productivity in the form of scholarly publications by Malaysian researchers increased more than threefold between 2007 and 2012, the highest increase in the world, and the number of citations grew fourfold from 2005 to 2012 (Malaysia, Ministry of Education 2015).

The universities in China, especially the research-intensive universities, have mandated their academics to publish in only indexed and impact-factored journals to garner more citation impact and to achieve academic legitimacy (Nature Publishing 2015; Xu 2016). Also, increasingly Malaysian universities have mandated their academic researchers to publish only in journals indexed by the Web of Science (Abrizah et al. 2013). Malaysian scholars are also prioritizing submissions of papers to journals indexed in global citation databases, reflecting that they regard these journals as trustworthy and authoritative, leading local journals to receive fewer good quality paper (Bodaghi, Sanni and Zainab 2015). An attempt was made to understand what resources Malaysian scholars choose for their reading, citing and publishing purpose and what their reasons are (Abrizah et al. 2015). Conscious that how non-native English language researchers, having to deal with both English language publications and their own national publications, might think and behave differently, CIBER's study questionnaire and associated methods (Tenopir et al. 2013) was replicated with researchers from Malaysia (Abrizah et al. 2016) and China (Nicholas et al 2016). So any evidence that scholars, especially from peripheral countries and the NICs, might be adopting different habits in what they read and cite and where they publish as well as disseminate their findings is clearly of interest and that is primarily what we wish to demonstrate in this paper. Therefore, the objective of this study is determine how scholars from Malaysia characteristically behave in regard to trust and authority in their scholarly communication activities, determine whether they act differently in regard to sources and channels that originate from the core countries and the peripheral countries. The results of this study, led by University of Malaya, is compared with that of the Chinese study, led by Wuhan University on trustworthiness and quality determination in scholarly reading, citing, and publishing. 


\section{LITERATURE REVIEW}

Scholars have particularly stringent requirements for high quality, reliable and reputable information sources and channels for scholarly communication. The notion of trust and authority in scholarly communications has been examined quite extensively, and from a variety of requirements. These requirements have traditionally been operationalised as conventional indicators especially for articles cited in or submitted to journals. These indicators include (a) presence or absence of scientific peer reviewing processes prior to the publication of the article (Bornmann 2011; Harnad 1999; Rowland 2002; Resnick and Almore 2016; Wicherts 2016), (b) post-publication assessments by means of comments and review articles (Eyre-Walker and Stoletzki 2013; Nentwich 2005; von Elm, Wandel and Jueni 2009); (c) citations received by an article (Bornmann and Daniel 2008; Cronin 1984; Haddawy et al. 2016), (d) Journal Impact Factor (Abramo, D'Angelo and Di Costa 2010); Garfield 1986; Simpson 2015), (e) the reputation of the channel used to communicate the article (Ahlgren and Waltman 2014; Kling 2004), and (e) the author's or publisher's reputation and institutional affiliation (Abrizah et al. 2015; Becher and Trower 2001; Allen and Heath 2013).

A discussion of the connection of trust and scientific knowledge and communicating how scholars read and use, cite and publish their research work provides for the topical framing. For the purpose of assessing scholarly content, traditional criteria are held to be important and there is still little empirical evidence of the acceptance of a "collaborative and Web 2.0 inspired scholarly communication" by researchers (Ponte and Simon 2011, p. 149). Ponte and Simon (2011) found that researchers considered the presence of journal articles in citation indexes and reputation of the publishing venue, are the most important; publications in open access journals and the number of occurrences in personal blogs or web sites are considered less relevant; and the presence in social bookmarking systems is considered not very relevant at all. Among the different characteristics of a research article, which are considered when taking the decision what to read, the source of the article and the title of the journal figure highly, as high as its online presence, though not as high as its topic. Tenopir et al. $(2010 ; 2011)$ reported that the highest rated articles are those written by: (a) a top-tier author, in a peer reviewed journal, available online at no personal cost to the reader; (b) by a top-tier author, in a peer-reviewed journal not in the top tier, available online at no personal cost to the reader. Many studies had demonstrated that researchers in the sciences tend to read more in electronic journals or from e-prints than do humanists or those in the social sciences (Rusch-Feja and Siebeky 1999); Tenopir et al. 2009) although Vakkari (2008) has shown that when normalising for availability, humanities faculty are no less inclined to use electronic journals. However, Kurata et al. (2009) and Ronellenfitsch et.al. (2015) found that in an age of online publication, medical researchers still preferred reading the printed versions of articles and preferred subscribed journals. Open access platforms were not recognized as one possible route for obtaining journal articles although PubMed Central constituted about 10 percent of the most recently read e-journals (Kurata et al. 2009).

The literature shows that the prime motivations for citing other people's work, across all disciplines, are the perceived authority of the cited material or of its author or of its dissemination channel. Research Information Network (2009) reported that personal contact has little or no influence in how UK-based researchers decide to cite an author, although early career researchers (ECRs) are more likely to cite more and to be influenced by the authority of the author cited. ECRs also testified receiving advice from reviewers and coauthors, and they tailor their citations to meet to the real or perceived requirements of specific journals. Disagreement with previous findings and easy accessibility to articles are among the significant reasons for citing across all disciplines (Research Information Network 
2009). In earlier studies, Evans (2008) and Kurtz et al. (2005) found that the availability of journal articles online has resulted in authors citing fewer older articles and a narrower diversity of sources.

In deciding where and how to communicate their work, researchers have to make choices between speedy dissemination to a desired audience, and less speedy publication in a highstatus journal (Research Information Network 2009). Peer-review seems to be one pivotal criterion that many scientists employ in evaluating the legitimacy of publication venues (Weller 2001). Tenopir (2003) indicated that peer-reviewed journals are more accepted and used by scholars because they are free of cost and accessible. Kling, Spector and McKim (2002) believed that scholars would have a better chance to use Internet resources to improve the dissemination of their research if a wider array of publishing models is available besides electronic journals and hybrid paper-electronic journals.

Special attention in this review is paid to the pervasiveness of digital technologies in formal scholarly communication processes through Open Access and self-archiving publishing model. Open Access journals whose aim is to maximise dissemination of research output, are specifically noted incentives for publishing of due to free access and visibility. Despite the well-known successes of Open Access and self-archiving publishing models, researchers still prize publication in key journals. Authors choose open access over more traditional and respected subscription based publications, unless the quality issue is also addressed (Warlick and Vaughan 2007). Frandsen (2009) compared the open access journals usage in developing and developed countries and revealed that authors from developing countries less cite Open Access journals compared to those from developed countries. However, the use Open Access platforms to disseminate research was met with general skepticism due to lack of peer review. Although multiple studies have reported that the impact of Open Access citations often surpasses those published in non-Open Access publications (Antelman 2004; Harnad and Brody 2004), Open Access journals are accepted by scientists only if peer-reviewed. Social scientists are suspicious and confused about Open Access publications, but not if they come from a traditional publisher (Nicholas et al. 2014).

Other essential scholarly communication evaluation criteria accumulated throughout the years to complement to the traditional peer review is usage based metrics (Cronin, 2001). New refined metrics have increasingly been developed to analyse the performance of a journal, an author or an article (Priem and Hemminger 2010; Taylor and Kamalski 2012) such as based on page views and downloads (Thelwall and Kousha, 2015), blogs (Shema, Bar-Ilan, and Thelwall 2014) and web links (Kousha and Thelwall 2014; Mas Bleda et al. 2014) as well as altmetrics (Mohammadi et al. 2015; Zuccala et al. 2015). Though scientists do use online tools and services that are directly germane to their research interests and that allow them to replicate experiments or delve more deeply into the material supporting a refereed paper, they generally do not use blogs, wikis, social networking sites, and similar online technologies. However, as CIBER's studies have pointed out, these attitudes are slowly changing (Nicholas and Rowlands, 2011; Rowlands et. al 2011; Tenopir et al. 2013).

This review has shed light on a wide range of issues relating to how researchers decide when, where and how to communicate their findings. Overall, the studies on how scholars establish trust in reading, citing and publishing in the current digital environment are limited and pioneered by CIBER (Nicholas et al. 2014, Tenopir et al. 2015), covering USA and the UK. The most recent study by Nicholas et al. (2015a) examined how trustworthiness is defined in digital environment in terms of scholarly reading, citing and publishing. Their study confirmed that peer review is still the most trustworthy characteristics for scholars' reading, 
citing and publishing. Jamali et al. (2014) extended the study and identified factors which influence how academic scholars in different geographical regions establish trust in deciding to read, cite and publish. Their findings showed that scholars from developing countries such as India and China were motivated by external factors of article such as authority and publisher's reputation. However, the factors which are more important for scholars from developed countries such as USA and UK are the citation practices and whether or not the source has been peer reviewed. And in the current study, we shall establish whether that has come about for Malaysia, a country currently on the 'periphery' of the scholarly endeavour, and compare with an earlier study of Chinese (Nicholas et al. 2016), using the methods and questions of which were replicated from CIBER's (Tenopir et al. 2013) study.

\section{OBJECTIVES}

The objectives of this paper are twofold:

a) To compare whether Malaysian and Chinese researchers are different in the way they assess trustworthiness and quality in regard to their scholarly reading, citing and publishing.

b) To show how they perceive changes in trust in the light of the emergence of new forms of scholarly communication, such as open access publications and social media.

The comparison in is done loosely based on mean ranking of statements because of the following reasons:

(a) there are some differences in the ways scholars were recruited to the surveys;

(b) the sizes and demographics of the samples differ. These differences are detailed in the methodology section.

\section{METHOD}

In order to make the research results comparable, both surveys adhere to the research scope and method that CIBER developed and used in its previous studies (Tenopir et al. 2013). The Sloan questionnaire, which had been pilot-tested (Jamali et al. 2014), was adopted. In the questionnaire researchers were asked a total of 24 questions regarding their use of scholarly information, citation and publishing practices, and their personal demographics. The core of the questionnaire relied on Likert scales ranking the importance or agreement with views and statements about the trustworthiness of a source/channel in regard to these three key scholarly activities. The questions were measured on a 5- point scale, and the values from 1 to 5 to the options from "strongly disagree" to "strongly agree", the options from "not important" to "very important" and the options from "not characteristic" to "essential" were assigned. The statements, opinions and activities listed in the questions were sourced from critical incidence interviews and focus groups, which were conducted to in order to scope the survey and frame the survey questions.

The questionnaire for Malaysian researchers went online for three months, in early October 2014, and closed in December 2014. The online survey tool, Survey Monkey.com was used to execute the survey by sending e-mail messages linking authors to the web-based questionnaire. During that time, a total of 514 responded to the survey, from a target sample of 2500 , a 20.56 percent participation rate. The response rate is exceptionally good for an online survey as Gravetter and Forzano (2009) indicated a typical response rate for online 
survey is only about 18 percent. It is also statistically stronger than the China survey. Although in total, 514 authors responded to the survey, different number of respondents completed the various parts of the survey questions, of which the number of responses reduced or degraded towards the end of the questionnaire, most probably because there were respondents who felt that the survey was too long to be completed. Therefore, in the process of data analysis, only the mean value, which is the most popular and well-known measure of central tendency, of each statement is worthy to pay attention to and included all responses to each statement.

The questionnaire for Chinese researchers was distributed in two approaches: first, with the help of Springer who sent out an invitation to 10,000 authors to take part in the survey, also hosted on SurveyMonkey.com. The web-based survey was conducted during April to May 2014. A total of 397 responses were received. The second approach was to upload the questionnaire on Sojump.com, i.e. a Chinese survey website. John Wiley and Sons, Inc., Sage Publication, Taylor \& Francis and three other publishers were requested to send out an invitation to Chinese authors to take part in the Sojump.com questionnaire. This questionnaire was made available between March and May 2014. A total of 265 responses were obtained through the second approach, giving a total number of 662 responses. Because the researchers were not sure how many surveys were distributed to unique potential respondents, a response rate (there would inevitably be an overlap) could not be calculated.

The mean value was calculated, and the higher the mean value means respondents rated the statement on trustworthiness and quality in regard to their scholarly reading, citing and publishing more important or agreed more strongly with that particular statement. The means of the scores were then computed and the practices listed in rank order of popularity.

\section{Respondents Demographics}

Respondents from Malaysia were all affiliated to Malaysia-based institutions. Although all respondents from China were Chinese, some of them (15\%) also worked or affiliated to universities in other countries, including Canada, the United States, Japan, Taiwan, Thailand, Singapore, the United Kingdom, Vietnam and Germany. The average age of the respondents is 41 and 33 years for Malaysian and Chinese researchers respectively. For unknown reasons, only a total of 391 Malaysian respondents specified their specific research fields and after reclassification of their research areas, the social scientists (38.1\%) comprised the majority of the survey respondents, followed by physical scientists (32.8\%), life scientists (14.1\%) and humanists (6.6\%). Regarding Chinese respondents, 54.0 percent were from the physical sciences, 26.0 percent biosciences, 16.0 percent social sciences and 4.0 percent humanities. Thus the Chinese group was not just significantly younger, it was also more heavily skewed to the physical sciences (Malaysian study was skewed towards the social sciences). Therefore, comparisons need to be made with caution.

The Malaysian respondents comprised 54.2 percent females and 45.3 percent males and a balance of sciences $(46.9 \%)$ and non-sciences $(44.7 \%)$. The Chinese has comparatively more male $(78.0 \%)$ and science $(80.0 \%)$ than female $(22.0 \%)$ and non-science researchers among their respondents. The majority of Malaysian respondents representing 60.1 percent of those working at research-intensive university, 30.9 percent are working at primarily teaching university/college, and 4.1 percent are working at a government agency, 1.0 percent at a hospital or medical school, and 1.8 percent are working at a research institutes. The rest came from other types of organizations. A total of 46.0 percent Chinese researchers reported working in research intensive universities, 20.0 percent from research institutes, 16.0 
percent from teaching universities and 9.8 percent from hospitals or medical schools. The rest came from a miscellany of organisations. Table 1 presents the demographics comparing Malaysia and China.

Table 1: Comparison of Respondents Demographics

\begin{tabular}{l||r||r}
\hline \hline \multicolumn{1}{l||}{ Characteristics of respondents } & \multicolumn{1}{c|}{ Malaysia } & \multicolumn{1}{c}{ China } \\
\hline \hline Sample (number) & 514 & 662 \\
\hline \hline Male (Percentage) & $45.7 \%$ & $78.0 \%$ \\
\hline \hline Female (Percentage) & $54.3 \%$ & $22.0 \%$ \\
\hline \hline Average age (year) & 41 & 33 \\
\hline \hline Sciences (Percentage) & $46.9 \% *$ & $80.0 \%$ \\
\hline \hline Non-Sciences (Percentage) & $44.7 \% *$ & $20.0 \%$ \\
\hline \hline Research-intensive university (Percentage) & $60.1 \%$ & $46.0 \%$ \\
\hline \hline Teaching universities (Percentage) & $30.9 \%$ & $16.0 \%$ \\
\hline \hline Research institutes (Percentage) & $1.8 \%$ & $20.0 \%$ \\
\hline \hline
\end{tabular}

* $8.4 \%$ did not indicate their research area

\section{RESULTS AND DISCUSSIONS}

The results section is divided into four parts. The first three parts covers matters of trustworthiness in regards to the three traditional scholarly activities: (a) using and reading information sources; (b) citing behaviour; and (c) publishing and dissemination. The fourth section looks at changes in trustworthiness over time.

\section{Using and Reading Information Sources}

This is the most common scholarly activity of the three and the least prescribed, so there is more scope here for innovation and experimentation. Two questions asked researchers about their using/reading behavior. The first asked about the importance of 16 activities mentioned by focus group participants (Abrizah et. al 2015; Tenopir et al. 2013) as being undertaken to determine what to use/read. The second asked about their agreement with a range of assertions made by interviewees/focus group participants about the attributes of a range of information sources.

Table 1 lists the 16 usage activities authors considered important when deciding what information to use or read in their own research areas. Researchers were asked to rate the importance of each task on a scale of Extremely Important (5), Very Important (4), Important (3), Somewhat Important (2), or Not Important (1) and the activities are listed in ranked order based on the mean score. The higher the mean value, then more important the activity is. In terms of importance, 4 out of 16 statements receive a mean score of more than 4.0 for both Malaysian and Chinese researchers, i.e. the tendency towards very important.

The very fact that 10 of the activities were rated as being "important" or "somewhat important" by both Malaysian and Chinese researchers, demonstrates what that there are many ways of determining usage. It is clearly a complex task. Turning to similarities and differences between Malaysian and Chinese researchers, in fact, there was an agreement between them in the top five most important activities and the least important. Despite opportunities for innovation afforded by the digital environment, the most highly rated activities were, in fact, long established ones, i.e. reading the abstract. This was the highest importance score recorded for both Malaysian and Chinese surveys. Abstracts are an artefact 
of a pre-digital world where the opportunities for accessing the full-text were severely limited. This is perhaps a case of researchers reaching back in time for something that would help them float the digital tide.

In general, authors emphasized much importance on reading and internal checking of arguments, methods and data (Statement ranked 1 to 5 , all obtaining an extremely important rating of 4 or more), then they would move on to other important activities such as checking the reputation of the journals that published the articles (name, publisher, indexation status).. Of least importance, but nevertheless still rated somewhat important, was checking whether the author came from a country noted for its research. Peer review assessment was also seen as important by Chinese scholars who rated it $9^{\text {th }}$ in importance as compared to Malaysian scholars, who rated it $7^{\text {th }}$.

Table 1: Activities Undertaken by Malaysian and Chinese Researchers when Determining what to Use and Read (Mean Importance Ranking)

\begin{tabular}{|c|c|c|c|c|}
\hline $\begin{array}{l}\text { Rank } \\
\text { (Msia) }\end{array}$ & Activity Statement & $\begin{array}{l}\text { Mean } \\
\text { (Msia) }\end{array}$ & $\begin{array}{l}\text { Mean } \\
\text { (China) }\end{array}$ & $\begin{array}{l}\text { Rank } \\
\text { (China) }\end{array}$ \\
\hline 1 & Reading the abstract & 4.34 & 4.56 & 1 \\
\hline 2 & $\begin{array}{l}\text { Reading the information source (article, book chapter, etc.) in its } \\
\text { entirety }\end{array}$ & 4.34 & 3.84 & 5 \\
\hline 3 & Checking the methods & 4.18 & 4.06 & 3 \\
\hline 4 & Checking to see if the data used in the research are credible & 4.03 & 4.01 & 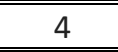 \\
\hline 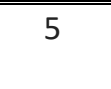 & $\begin{array}{l}\text { Checking if the arguments and logic presented in the content are } \\
\text { sound }\end{array}$ & 3.97 & 4.12 & 2 \\
\hline 6 & Checking the figures and tables & 3.70 & 3.77 & 6 \\
\hline 7 & Checking to see if it is peer reviewed & 3.66 & 3.34 & 9 \\
\hline 8 & $\begin{array}{l}\text { Checking to see means by which it has been } \\
\text { disseminated/published (e.g. subscription journal, Open Access } \\
\text { journal, a repository, a blog) }\end{array}$ & 3.65 & 3.22 & 8 \\
\hline 9 & Checking the name of the journal & 3.64 & 3.58 & 10 \\
\hline 10 & $\begin{array}{l}\text { Checking whether the source is indexed by an authoritative } \\
\text { indexing body (e.g. ISI, PubMed) }\end{array}$ & 3.61 & 3.63 & 7 \\
\hline 11 & Checking the name of the publisher & 3.53 & 2.75 & 14 \\
\hline 12 & Checking the name of the author & 3.04 & 2.73 & 13 \\
\hline 13 & $\begin{array}{l}\text { Taking account of where it was obtained from (e.g. publisher's } \\
\text { website, university library catalogue, search engine) }\end{array}$ & 2.99 & 2.74 & 12 \\
\hline 14 & $\begin{array}{l}\text { Checking to see how many times it has been downloaded/ } \\
\text { accessed }\end{array}$ & 2.80 & 3.00 & 11 \\
\hline 15 & Taking into consideration a colleagues' opinion & 2.73 & 2.64 & 15 \\
\hline 16 & $\begin{array}{l}\text { Checking whether author's country of affiliation is known for its } \\
\text { research }\end{array}$ & 2.65 & 2.60 & 16 \\
\hline
\end{tabular}

Determining what to use on the basis of the number of downloads received, a relatively new digital indicator, was rated low in importance, so metrics are not being widely seen as a surrogate for quality. The Chinese scholars rated this usage activity $11^{\text {th }}$ in importance as compared to $14^{\text {th }}$ for Malaysian, showing a lesser belief in altmetrics as trust proxies. If anything, this study suggests that trust in altmetrics has not improved, though there are clear indications that this is not the case for everyone. For example, young scholars (aged 30 and under) are much more likely to believe that checking to see how many times an article is downloaded and taking account of colleagues' opinions is important when deciding what they trust as readers (Jamali et al. 2014). 
Perhaps the biggest surprise was how relatively lowly a colleague's opinion and author's country of affiliation were, both from Malaysian and Chinese authors' perspective. This is perhaps due to scholars making usage decisions in real-time, or because they view usage as not important enough to merit consulting a colleague or from where the author is. Overall findings suggest that, in general, researchers are making reading and using decisions based on the content of an article, rather than on external attributes and reputations of authors, journals, or publishers.

The second question about usage/reading asked researchers whether they agreed with 8 statements concerning the trustworthiness or otherwise of a range of information sources. The scale was: Strongly agree (5), Agree (4), Slightly agree (3), Disagree (2), Strongly disagree (1). Again, there was an agreement between the two countries in the top three most important activities (Table 2). For scholars from both countries, peer reviewed still have irreplaceable effect on promoting trustworthiness of information source even though it is a traditional means of quality control of journals. Similar to the international scholars' perspective that "peer-review is still king" (Nicholas et al. 2015), this is ranked first by the Malaysian researchers and second by the Chinese. Peer reviewed journals are still the most trusted and preferred vehicle for scholarly communication. If anything, this study suggests that trust in peer review has increased, though there are clear indications that this is not the case for everyone. So, for example, while life scientists see peer review as critical, young scholars (aged 30 and under) are more likely to also trust other, less traditional forms of scholarly communication, such as social media (Tenopir et al. 2013).

Malaysian researchers also think the information sources recommended by their colleagues are more credible and trustworthy. Interestingly, Chinese researchers agreed the most with the statement about reading an article recommended by a colleague, and this does appear at odds with what they said in the first question.

There was a value of Journal Impact Factor in determining quality and trustworthiness of information source by Malaysian scholars, as compared to Chinese researchers, who ranked this the lowest. Wikipedia as a trustworthy information source received the lowest ranking by Malaysian researchers. In general, both Malaysian and Chinese researchers opted for neutrality for the other statements, albeit leaning towards agreement.

Malaysian and Chinese researchers were very much in agreement on the statements about the trustworthiness of information sources for usage purposes, with the rankings for 7 and 6 (respectively) out of the 8 statements either being identical or within one place of each other (Table 2). None of the statements were identically ranked between the Malaysian and Chinese researchers. Malaysian and international researchers were in agreement with peer-reviewed, impact factor and availability as indicators of trustworthiness in using and reading. Therefore, the exceptions were that Chinese researchers were more likely to agree that they opted for easy of availability (rank 5 as compared to 7 for Malaysian) as compared to the importance of impact factor (rank 8 as compared to 4 Malaysian). 
Abrizah, A., Xie, J. \& Nicholas, D.

Table 2: Views of Malaysian and Chinese Researchers on Statements about the Trustworthiness of Information Sources for Usage Purposes (Mean Agreement Ranking)

\begin{tabular}{c|l|c||c|c}
\hline \hline $\begin{array}{c}\text { Rank } \\
\text { (Msia) }\end{array}$ & \multicolumn{1}{|c|}{ Activity Statement } & $\begin{array}{c}\text { Mean } \\
\text { (Msia) }\end{array}$ & $\begin{array}{c}\text { Mean } \\
\text { (China) }\end{array}$ & $\begin{array}{c}\text { Rank } \\
\text { (China) }\end{array}$ \\
\hline 1 & $\begin{array}{l}\text { Peer reviewed journals are the most trustworthy } \\
\text { information source. }\end{array}$ & 4.08 & 3.95 & 2 \\
\hline 2 & $\begin{array}{l}\text { My main criteria on for finding out if a source is } \\
\text { trustworthy is the content itself }\end{array}$ & 3.94 & 3.92 & 3 \\
\hline 3 & $\begin{array}{l}\text { I am very likely to read an article recommended to me } \\
\text { by a colleague }\end{array}$ & 3.73 & 4.05 & 1 \\
\hline 4 & $\begin{array}{l}\text { The journal's Impact Factor is important for deciding } \\
\text { what to read. }\end{array}$ & 3.71 & 3.45 & 8 \\
\hline 5 & $\begin{array}{l}\text { Open Access publications that are peer reviewed are } \\
\text { trustworthy }\end{array}$ & 3.66 & 3.75 & 4 \\
\hline 6 & $\begin{array}{l}\text { When pressed for time, the ease of availability of a } \\
\text { source over-takes considerations about its quality }\end{array}$ & 3.37 & 3.55 & 7 \\
\hline 7 & $\begin{array}{l}\text { If the information is not central to my research area, the } \\
\text { ease of availability of a source is more important than its } \\
\text { quality. }\end{array}$ & 3.22 & 3.66 & 5 \\
\hline 8 & Wikipedia has become more trustworthy over the years & 3.04 & 3.56 & 6 \\
\hline \hline
\end{tabular}

\section{Citing Information Sources}

In terms of scholarly importance, citing comes somewhere between usage and publishing. Researchers read many articles, however cite only a few of them, so selection is required and trustworthiness is assessed as part of the process. Citing is a prescribed and important activity for scholars, closely associated with publishing, and comes with guidelines and rules. Two questions in the surveys asked about citing behavior. The first explored the customary practices of the researchers' discipline in relation to their citation practices, in other words, the respondents were asked if their citation practice is a characteristic of their research discipline. The second asked if scholars agreed with a number of statements regarding their citation practices.

Regarding the first question, 12 citation practices, mentioned in the interviews/focus groups, were presented and researchers were asked to consider how characteristic of their field each was and rate it on a five-point scale (essential 5; very characteristic 4; characteristic 3; somewhat characteristic 2 and not characteristic 1 ). The question was not asked directly of the individual because it was felt that researchers might not answer honestly (as some of the practices might be seen as 'citation gaming'), but about the prevalence of the practice in their own discipline. Findings (Table 3 ) indicate that the top three citation practices which are common across disciplines for the two research communities are citing: (a) the most recent source; (b) the most highly cited source; (c) seminal information published on a topic. Citing the most recent resources proved to be the most characteristic practice among Malaysian, whereas the Chinese ranked this second.

Researchers also reported cite decisions that are not related to quality of sources. 'Citation gaming' practices have been identified as characteristics and were ranked at 5, 6 and 7, by both Malaysian and Chinese scholars, i.e. (a) papers mentioned by reviewers to increase 
chances of acceptance; (b) papers in the journal to which an article is submitted for publication to increase chances of acceptance; and (c) one's own work to improve one's citation ranking, such as $\mathrm{h}$-index. There were only small differences in views between these two communities.

Table 3: Characteristic Citation Practices in Field of Study as Viewed by Malaysian and Chinese Researchers (Mean Characteristic Ranking)

\begin{tabular}{c||l|c|c|c}
\hline \hline $\begin{array}{c}\text { Rank } \\
\text { (Msia) }\end{array}$ & Activity Statement & $\begin{array}{c}\text { Mean } \\
\text { (Msia) }\end{array}$ & $\begin{array}{c}\text { Mean } \\
\text { (China) }\end{array}$ & $\begin{array}{c}\text { Rank } \\
\text { (China) }\end{array}$ \\
\hline \hline 1 & Citing the most recent source published on a topic & 3.93 & 3.71 & 2 \\
\hline \hline 2 & Citing the most highly cited information sources & 3.79 & 3.70 & 3 \\
\hline \hline 3 & $\begin{array}{l}\text { Citing the seminal information source published on a } \\
\text { topic }\end{array}$ & 3.55 & 3.90 & 1 \\
\hline 5 & Citing the first information source published on a topic & 3.54 & 3.68 & 4 \\
\hline \hline 6 & $\begin{array}{l}\text { Citing papers mentioned by reviewers to increase chances } \\
\text { of acceptance }\end{array}$ & 3.46 & 3.23 & 5 \\
\hline \hline 7 & $\begin{array}{l}\text { Citing papers in the journal to which an article is } \\
\text { submitted for publication to increase chances of } \\
\text { acceptance }\end{array}$ & 3.37 & 3.09 & 6 \\
\hline \hline 8 & $\begin{array}{l}\text { Citing one's own work to improve one's citation ranking } \\
\text { (e.g. H-Index) }\end{array}$ & 3.12 & 2.94 & 7 \\
\hline \hline 9 & $\begin{array}{l}\text { Citing the published version of record, but reading } \\
\text { another version found on the open web }\end{array}$ & 2.63 & 1.98 & 12 \\
\hline \hline 10 & $\begin{array}{l}\text { Citing, if possible, only sources published in developed } \\
\text { countries }\end{array}$ & 2.52 & 2.24 & 9 \\
\hline \hline 11 & $\begin{array}{l}\text { Citing sources disseminated with comments posted on a } \\
\text { dedicated website (open peer review) }\end{array}$ & 2.51 & 2.13 & 10 \\
\hline \hline 12 & $\begin{array}{l}\text { Citing a pre-print which has not yet been accepted by a } \\
\text { journal }\end{array}$ & 2.41 & 2.12 & 11 \\
\hline \hline
\end{tabular}

Clearly citing non-peer reviewed sources, including the social media, appears to be out of the question and being ranked among the last by Chinese scholars. Surprisingly the Malaysian scholars placed this at a higher mean score. There was not much difference in the placing of open review sources with Chinese researchers placing it slightly higher than Malaysian ( $8^{\text {th }}$ as compared to $\left.9^{\text {th }}\right)$, but in these cases researchers indicated the practice as only being "somewhat characteristic".

Citing, only sources published in developed countries received a relatively lower rank by both communities and this show that many researchers feel that citation practices based on regions are "somewhat characteristic" of their discipline. This shows that researchers hardly cite sources published in developed countries. Citing a pre-print which has not yet been accepted by a journal also received relatively lower rank probably because these "publications" had not been reviewed.

The second citation question asked the researchers whether they agreed with 11 statements about their citing practices and behaviours. Researchers rate each statement on a scale of: 
Strongly agree (5), Agree (4), Slightly agree (3), Disagree (2), Strongly disagree (1). Table 4 presents the findings. In terms of agreement of the quality and trustworthiness of the sources cited, 9 out of 11 statements received a mean score of more than 3.0 by both Malaysian and Chinese, i.e. the tendency towards agreement. Authors in general confessed exercising caution with the selection of sources cited, and rigidity in citing an article, compared to reading it.

Table 4: Views of Malaysian and Chinese Researchers on Statements about the Trustworthiness of Sources for Citation Purposes (Mean Agreement Ranking)

\begin{tabular}{|c|c|c|c|c|}
\hline $\begin{array}{l}\text { Rank } \\
\text { (Msia) }\end{array}$ & Activity Statement & $\begin{array}{l}\text { Mean } \\
\text { (Msia) }\end{array}$ & $\begin{array}{l}\text { Mean } \\
\text { (China) }\end{array}$ & $\begin{array}{c}\text { Rank } \\
\text { (China) }\end{array}$ \\
\hline 1 & $\begin{array}{l}\text { I have no problem citing an article published in an Open } \\
\text { Access journal if it has been properly peer reviewed }\end{array}$ & 3.92 & 3.63 & 5 \\
\hline 2 & $\begin{array}{l}\text { From a trust perspective I'm more easy-going in what I read } \\
\text { than what I cite. }\end{array}$ & 3.75 & 3.79 & 2 \\
\hline 3 & $\begin{array}{l}\text { The journal Impact Factor is important for deciding what to } \\
\text { cite. }\end{array}$ & 3.62 & 3.85 & 1 \\
\hline 4 & $\begin{array}{l}\text { I prefer to cite articles published in an Open Access journal } \\
\text { only if they are of a reputable publisher. }\end{array}$ & 3.59 & 3.34 & 9 \\
\hline 5 & $\begin{array}{l}\text { Social media mentions/likes are indications of popularity } \\
\text { only, not credibility. }\end{array}$ & 3.56 & 3.75 & 3 \\
\hline 6 & $\begin{array}{l}\text { Social media mentions/likes are indications of popularity } \\
\text { only, not quality. }\end{array}$ & 3.55 & 3.74 & 4 \\
\hline 7 & $\begin{array}{l}\text { Usage metrics are indications of popularity only, not } \\
\text { credibility }\end{array}$ & 3.43 & 3.47 & 7 \\
\hline 8 & Usage metrics are indications of popularity only, not quality. & 3.42 & 3.57 & 6 \\
\hline 9 & $\begin{array}{l}\text { I only cite conference proceedings if there's no other } \\
\text { alternative because the work there is still speculative, and, as } \\
\text { such, a little unreliable. }\end{array}$ & 3.30 & 3.45 & 8 \\
\hline 10 & I tend to cite people I know because I trust them & 3.23 & 2.99 & 10 \\
\hline 11 & $\begin{array}{l}\text { I don't cite articles published in Open Access journals } \\
\text { because they are of low quality. }\end{array}$ & 2.57 & 2.71 & 11 \\
\hline
\end{tabular}

Open Access is more welcomed by both Malaysian compared to the Chinese scholars. Open Access facilitates greater access and authors indicated Open access journals help them in making decision to cite articles related to their research, and the study suggests that citing a paper from an open access journal is a good idea only if the open access journal is peerreviewed and published by reputable publishers. Findings also indicate that authors agree that citing a paper from an open access journal has nothing to do with quality (ranked $11^{\text {th }}$ by both communities). Unfortunately, many open access journals are predatory and they accept too many papers of a low scientific quality that will be never cited (Beall 2016).

Journal impact factor adds credibility to the authors for citing a source. The importance of the journal impact factor was the most agreed on statement by the Chinese researchers (ranked $1^{\text {st }}$. Malaysian authors ranked the statement $3^{\text {rd }}$, however, international scholars seemed to agree that citing a paper from impact-factored journal has nothing to do with quality (Tenopir et al. 2013).

Citing authors who they know was not a practice that obtained much support by Malaysian and Chinese research communities. Views about (implied) citing on the basis of high altmetrics, such as mentions, likes and use are yet to form and would the practices would be 
more common among the international researchers (Tenopir et al. 2013) compared to their Malaysian and Chinese counterparts. Authors in general agree that social media usage (e.g. downloads) and derived metrics (e.g. likes and mentions) are indicators of popularity, not credibility and quality. Conference papers are perceived as less authoritative to be cited by these two research communities.

\section{Publishing and Disseminating Research}

Publishing and disseminating research is a crucial portion of the scientific process, as this the activity on which research careers and reputations are made. Trustworthiness in journal selection for publication is particularly important to academics because it is the peerreviewed journal articles that receive the most notice from promotion panels and research committee, and to strengthen their careers, researchers need to publish in sources that are widely held to be of prestige, high quality and widely trusted (Jamali et al. 2014; Nicholas et al, 2014). Given its importance, four questions in the surveys asked about publishing and disseminating research, namely about (a) the importance of outlet attributes when deciding where to publish; (b) institutional influences on publishing; (c) agreement with statements on the quality and trustworthiness of places to publish/disseminate research which were raised in the interview/focus groups. The fourth question was explicitly concerned with the burgeoning, somewhat controversial, open access publishing practice.

Ten scholarly publication outlet attributes highlighted by interviewees/focus group participants are listed in Table 5. Survey respondents were asked to rate the importance of each attribute on a scale of Extremely Important (5), Very Important (4), Important (3), Somewhat Important (2), or Not Important (1) and the mean calculated and ranked. All researchers have reached some kind of consensus on the most important attributes of an outlet when deciding where to disseminate/publish their research work pertaining to trust and authority: that journals must be highly relevant in their respective fields. Malaysian scholars emphasized their trust on peer-reviewed journals for publishing, and ranked this attribute second, compared to fourth by their Chinese counterparts. The Chinese's interest in trust proxies for publishing is inclined towards being indexed by a reputable indexing service, and highly cited, which they rated more highly that being peer-reviewed.

Table 5: Important Outlet Attributes for Malaysian and Chinese Researchers when Deciding where to Disseminate/Publish Research Work (Mean Importance Ranking)

\begin{tabular}{c||l|c|c|c}
\hline $\begin{array}{c}\text { Rank } \\
\text { (Msia) }\end{array}$ & \multicolumn{1}{|c|}{ Activity statement } & $\begin{array}{c}\text { Mean } \\
\text { (Msia) }\end{array}$ & $\begin{array}{c}\text { Mean } \\
\text { (China) }\end{array}$ & $\begin{array}{c}\text { Rank } \\
\text { (China) }\end{array}$ \\
\hline \hline 1 & It is highly relevant to my field & 4.29 & 4.24 & 1 \\
\hline \hline 2 & It is peer reviewed & 4.05 & 3.74 & 4 \\
\hline \hline 3 & $\begin{array}{l}\text { It is indexed by reputable/prestigious abstracting \& } \\
\text { indexing databases, such as Web of Science and Scopus }\end{array}$ & 4.01 & 3.95 & 2 \\
\hline 4 & It is published by a society in my field & 3.81 & 3.13 & 8 \\
\hline \hline 5 & It is highly cited & 3.80 & 3.89 & 3 \\
\hline \hline 7 & It is published by a traditional scholarly publisher & 3.58 & 3.32 & 6 \\
\hline \hline 8 & It has a reputable Editor/Editorial Board & 3.48 & 3.33 & 5 \\
\hline \hline 9 & It has both an online and a print version & 3.39 & 3.00 & 9 \\
\hline \hline 10 & It is Open Access & 3.10 & 2.71 & 10 \\
\hline \hline
\end{tabular}


There was another sign of Malaysian interest in trust proxies, with publication by society in the field rated more highly than that by traditional scholarly publisher. Malaysian and Chinese researchers rated traditional publishers (ranked $6^{\text {th }}$ ) lower than international scholars (ranked $3^{\text {rd }}$ ). The fact that an outlet is open access counts the least for Chinese researchers. Chinese researchers also thought the country in which the journal is located to be more important, rated $7^{\text {th }}$ as compared to last $\left(10^{\text {th }}\right)$ for Malaysian scholars.

The second aspect researchers were questioned was on the influence of institutional policies on their publishing behaviour. Research policies have tremendous influence on researchers when they publish their works. For instance, in Malaysian and Chinese research-intensive universities, at present Web of Science indexed journals are valued higher both by national educational authorities, the scientific community and by the universities themselves. Publishing in journals indexed by these citation databases would be a reasonable choice for almost all scholars who would want to be promoted, tenured, awarded or granted research funding. There was also a filter question, which asked whether research policy directives or mandates influenced where scholars publish their research. About 88 percent of the Malaysian researchers (452) felt that the research policy more or less influences their research works. On the other hand, 85 percent of Chinese researchers (562) said they were heavily or somewhat influenced by institutional/department/government research policy directives or mandates. Those researchers who said they were influenced were presented with a list of 7 possible influences and asked to rate them on a scale of: Extremely influenced (5), Very (4), Moderately (3), Slightly (2), or Not at all (1).

All in all, the tendency of publishing in high impact factor journals, in international journals, and in traditional sources i.e. journals and monographs is immensely influenced by policy directives and mandates among Malaysian and Chinese researchers (Table 6). At the other end of the scale, the researchers were barely pressed to publish in the social media. Blogging and micro-blogging to disseminate research findings are not influential as there are no forcible or encouraging measures for Malaysian and Chinese researchers to blog or tweet.There were a few important differences among the researchers, with Chinese researchers being more influenced to publish in an outlet that was also available in hardcopy (ranked $4^{\text {th }}$ as compared to $6^{\text {th }}$ by Malaysian researchers) and, unsurprisingly, less pressed to publish in national/local journals compared to Malaysian researchers.

Table 6: Research Policy Directives/Mandates and Their Influence on where Malaysian and Chinese Researchers Publish (Mean Strength Ranking)

\begin{tabular}{c||l||c||c||c}
\hline \hline $\begin{array}{c}\text { Rank } \\
\text { (Msia) }\end{array}$ & \multicolumn{1}{|c||}{ Activity statement } & $\begin{array}{c}\text { Mean } \\
\text { (Msia) }\end{array}$ & $\begin{array}{c}\text { Mean } \\
\text { (China) }\end{array}$ & $\begin{array}{c}\text { Rank } \\
\text { (China) }\end{array}$ \\
\hline \hline 1 & Publish in high Impact Factor journals & 4.03 & 3.97 & 1 \\
\hline \hline 2 & Publish in international journals & 3.99 & 3.94 & 2 \\
\hline 3 & Publish in traditional sources (e.g. journals and monographs) & 3.49 & 3.64 & 3 \\
\hline 4 & Publish in Open Access journals & 2.93 & 2.73 & 5 \\
\hline \hline 5 & Publish in national/local journals & 2.93 & 2.57 & 6 \\
\hline \hline 6 & Publish in sources that have a hard-copy version & 2.66 & 3.07 & 4 \\
\hline 7 & Write a blog and/or tweet about your research & 1.98 & 1.95 & 7 \\
\hline \hline
\end{tabular}

The third question asked researchers whether they agreed with 12 statements about the quality and trustworthiness and quality of publishing outlets. The scale was: Strongly agree (5), Agree (4), Slightly agree (3), Disagree (2), Strongly disagree (1) and the mean values are 
calculated and ranked in Table 7. The top three ranked statements all concerned the importance of publishing in peer reviewed, highly-ranked and reputable journals. Peer review journals were clearly thought to be the places to publish research; and there was little support for disseminating research via a blog among all three communities. There was only a little more support for promoting research via the social media reported by Malaysian researchers. The responses of Malaysian researchers were quite similar compared to their Chinese counterparts, with just one significant difference: Chinese were less likely to agree that publishing first in conference proceedings is a good way to test the veracity of my ideas, rated it at $11^{\text {th }}$, but $8^{\text {th }}$ by Malaysians.

Table 7: Views of Malaysian and Chinese Researchers on Statements about the Quality and Trustworthiness of Places to Publish/Disseminate Research (Mean Agreement Ranking)

\begin{tabular}{|c|c|c|c|c|}
\hline $\begin{array}{l}\text { Rank } \\
\text { (Msia) }\end{array}$ & Activity statement & $\begin{array}{l}\text { Mean } \\
\text { (Msia) }\end{array}$ & $\begin{array}{l}\text { Mean } \\
\text { (China) }\end{array}$ & $\begin{array}{c}\text { Rank } \\
\text { (China) }\end{array}$ \\
\hline 1 & $\begin{array}{l}\text { As peer reviewed journals are the most prestigious } \\
\text { place in which to publish, they are likely to contain high- } \\
\text { quality material. }\end{array}$ & 4.09 & 4.12 & 1 \\
\hline 2 & $\begin{array}{l}\text { To obtain research grants I have to publish in highly } \\
\text { ranked journals. }\end{array}$ & 4.09 & 3.80 & 3 \\
\hline 3 & $\begin{array}{l}\text { People who don't have tenure have to publish in good } \\
\text { journals to build up a reputation. }\end{array}$ & 3.90 & 3.83 & 2 \\
\hline 4 & $\begin{array}{l}\text { I publish in journals because a paper placed in a journal } \\
\text { obtains a context becomes part of a 'conversation' }\end{array}$ & 3.77 & 3.70 & 4 \\
\hline 5 & $\begin{array}{l}\text { Depositing a version of my published work in an } \\
\text { institutional repository increases usage and thereby } \\
\text { helps to build up my professional reputation among my } \\
\text { peers. }\end{array}$ & 3.56 & 3.65 & 6 \\
\hline 6 & $\begin{array}{l}\text { Depositing a version of my published work in an } \\
\text { institutional repository increases citation and thereby } \\
\text { helps to build up my professional reputation among my } \\
\text { peers. }\end{array}$ & 3.55 & 3.69 & 5 \\
\hline 7 & $\begin{array}{l}\text { I tend to publish first in conference proceedings, which } \\
\text { is a good way to test the veracity of my ideas. }\end{array}$ & 3.38 & 3.12 & 10 \\
\hline 8 & $\begin{array}{l}\text { I tend to publish first in a conference proceedings, } \\
\text { because it is a reliable way to reach my target } \\
\text { audiences. }\end{array}$ & 3.36 & 2.97 & 11 \\
\hline 9 & $\begin{array}{l}\text { My own website is central for ensuring the reliable } \\
\text { dissemination of my work to my target audiences. }\end{array}$ & 3.10 & 3.57 & 7 \\
\hline 10 & $\begin{array}{l}\text { I tend to publish first in a subject repository (pre- } \\
\text { publication database), such as ArXiv, PMC, RePEc, } \\
\text { because it is a reliable way to reach wider audiences. }\end{array}$ & 2.83 & 3.16 & 9 \\
\hline 11 & $\begin{array}{l}\text { I use social media (e.g. Twitter, blogs, social networks) } \\
\text { to get out information about my research because it is a } \\
\text { reliable way to reach my target audiences. }\end{array}$ & 2.72 & 3.21 & 8 \\
\hline 12 & $\begin{array}{l}\text { I tend to blog about the findings of my research, which } \\
\text { is a good way to test the veracity of my ideas. }\end{array}$ & 2.52 & 2.89 & 12 \\
\hline
\end{tabular}


The fourth question focused on open access publishing, something Malaysian focus group participants in an earlier study had trust concerns about (Abrizah et al. 2015). Researchers were presented with four statements and asked the extent to which they agreed with them. The scale was: Strongly agree (5), Agree (4), Slightly agree (3), Disagree (2), Strongly disagree (1) and the ranked mean values are provided in Table 8 . Interestingly, Malaysian and Chinese researchers had identical views on the topic of Open Access, therefore it would seem that these beliefs are held universally. They came closest to agreeing that open access helps poor countries to access scholarly publications. They appeared to be mildly disagreed with the implied criticism of open access publishing in the fourth ranked statement, which implied that the researchers do not believe that the reason for not publishing in an open access journal is question marks over quality.

Table 8. Views of Malaysian and Chinese Researchers on Statements about the Quality and Trustworthiness of Open Access Journals (Mean Agreement Ranking)

\begin{tabular}{c||c|c|c|c}
\hline \hline $\begin{array}{c}\text { Rank } \\
\text { (Msia) }\end{array}$ & \multicolumn{1}{|c||c|c|c}{$\begin{array}{c}\text { Activity statement } \\
\text { (Msia) }\end{array}$} & $\begin{array}{c}\text { Mean } \\
\text { (China) }\end{array}$ & $\begin{array}{c}\text { Rank } \\
\text { (China) }\end{array}$ \\
\hline 1 & $\begin{array}{l}\text { Open Access journals make trustworthy research } \\
\text { information accessible in countries where journal } \\
\text { subscriptions cannot be afforded. }\end{array}$ & 3.92 & 3.81 & 1 \\
\hline 2 & $\begin{array}{l}\text { I have no problem publishing in an Open Access journal } \\
\text { if it is properly peer-reviewed. }\end{array}$ & 3.92 & 3.63 & 2 \\
\hline 3 & $\begin{array}{l}\text { I publish in an Open Access journal only if it is published } \\
\text { by a reputable publisher }\end{array}$ & 3.83 & 3.62 & 3 \\
\hline 4 & $\begin{array}{l}\text { I don't publish in Open Access journals because they are } \\
\text { of low quality. }\end{array}$ & 2.68 & 2.79 & 4 \\
\hline \hline
\end{tabular}

\section{Changes over Time and Diversity}

With so many changes going on in the scholarly environment respondents we wished to find out what researchers made of it all. Were things getting better or worse and what are the ups and downs? In order to find out, researchers were presented with six possible scenarios on the changes that had happened over the past decade in scholarly communication and the extent of their agreement on the changes. The scale was: Strongly agree (5), Agree (4), Slightly agree (3), Disagree (2), Strongly disagree (1) and the rankings are provided in Table 9.

Regarding perceived changes over time and diversity, Malaysian researchers were more likely to believe that as there are more publication outlets, it is easier to get published and as a result, there is a flood of poor quality material. Chinese researchers, on the other hand were more likely to believe that their fields were experiencing increased pressure to publish and, thus, there is a flood of mediocre/poor quality materials.

Based on the mean agreement ranking, Malaysian researchers were more likely to believe that there is a less strict/ less rigorous peer review process and as a result, there is a flood of poor quality material compared to their Chinese counterparts. The latter groups felt that the peer review system is helping. Unlike the Chinese, Malaysian researchers were close to disagreeing that the closer ties they have with the researchers in their field (enabled by digital communication), the easier it is for them to judge the trustworthiness of material. 
Table 9 : Views of Malaysian and Chinese Researchers on Changes occurring in their Field of Study over the Past Decade (Mean Agreement Ranking)

\begin{tabular}{|c|c|c|c|c|}
\hline $\begin{array}{l}\text { Rank } \\
\text { (Msia) }\end{array}$ & Activity statement & $\begin{array}{l}\text { Mean } \\
\text { (Msia) }\end{array}$ & $\begin{array}{l}\text { Mean } \\
\text { (China) }\end{array}$ & $\begin{array}{c}\text { Rank } \\
\text { (China) }\end{array}$ \\
\hline 1 & $\begin{array}{l}\text { There are more outlets, it is easier to get published and as a } \\
\text { result, there is a flood of poor quality material }\end{array}$ & 3.46 & 3.72 & 3 \\
\hline 2 & $\begin{array}{l}\text { There is a less strict/ less rigorous peer review process and } \\
\text { as a result, there is a flood of poor quality material. }\end{array}$ & 3.41 & 3.50 & 7 \\
\hline 3 & $\begin{array}{l}\text { There is an increased pressure to publish and as a result, } \\
\text { there is a flood of mediocre/poor quality material. }\end{array}$ & 3.35 & 3.89 & 1 \\
\hline 4 & More researchers entering the field have raised standards. & 3.39 & 3.52 & 6 \\
\hline 5 & $\begin{array}{l}\text { There are more unethical practices (e.g. plagiarism, } \\
\text { falsifying, fabricating, citation gaming). }\end{array}$ & 3.20 & 3.58 & 4 \\
\hline 6 & $\begin{array}{l}\text { Easily available metrics make the evaluation of } \\
\text { trustworthiness easier }\end{array}$ & 3.29 & 3.53 & 5 \\
\hline 7 & $\begin{array}{l}\text { The closer ties with researchers in my field, enabled by } \\
\text { digital communication, make it easier for me to judge the } \\
\text { trustworthiness of material. }\end{array}$ & 3.29 & 3.72 & 2 \\
\hline
\end{tabular}

Findings on changes over time and diversity showed a remarkable consistency in terms of mean score across the board in respect to the importance of the traditional pillars of trust (content quality, peer review, journal), as we have seen here for Malaysian and Chinese researchers. However, it also exposed some differences among Malaysian researchers when it comes to the reasons for the flood of poor quality materials. In general the researchers were consistent in their agreement that more researchers have raised their publication standards, there are more unethical publication practices and that the available metrics make the evaluation of trustworthiness easier. This shows that the measures of establishing trust and authority do not seem to have changed profoundly in both Malaysia and China.

\section{CONCLUSIONS}

The study has shown views, perception and behaviours of authors in respect to scholarly channels and resource they trust to read and to cite. Measures of establishing trust and authority do not seem to have changed profoundly in Malaysia and China. The Internet technology has brought ease and convenience to scholarly communication and, more pressure is given to publish on high quality platforms, but there is a flood of poor quality material as a result of more publication outlet, less strict/less rigorous peer review process and more pressure to publish. Similar to studies by Nicholas et. al (2015b) Patel et. al (2017), peer-reviewed journals are still the central to the authors, however they seem to have more freedom in relation to journals they read and cite, compared to publish. Library and publisher platforms are still central to discovery of these journals, and social media appears to be more influential among scientists and early career researchers. Blogs and tweets would not be used in scholarly communication, and would be trusted only if written by prominent scholars. Researchers have moved from a print-based system to a digital one, but it has not significantly changed the way they decide what to trust. The digital transition has not led to a digital transformation. However, open access content appears to be trusted, with the 
proviso that it is peer reviewed and published by a reputable publisher.

In terms of usage there are really not many surprises or signs of new forms of scholarly behaviour taking strong hold. In fact, what comes over most strikingly is that researchers are very much involved in good old fashioned academic detective work when it comes to establishing what to use or read. Thus, internal content checks of arguments, methods are right at the top of their list, seen as being extremely important activities. And despite opportunities for innovation afforded by the digital environment, the most highly rated activity of all was that old stalwart of the pre-digital age, the abstract, which seems to have been reborn as a quality filter. Indeed abstracts are valued even more highly by Chinese researchers than Malaysian researchers. Trust surrogates, such as download data, are not viewed to be very important, however, more important than international researchers. Perhaps the biggest surprise is how relatively lowly a colleague's opinion on what to read is held, more lowly in fact than by international scholars.

Again, we find very traditional forms of behaviour with citing the seminal source on the topic proved be most characteristic of the disciplines. The Journal Impact Factor is also important for deciding what to cite, although this was not considered as the top source for determining quality and trustworthiness in Ameen's (2017) study of a developing country and in Watkinson et al. (2015) where researchers in the US and the UK tend to use personal judgement to decide on whether a particular journal could be trusted rather than using a proxy such as impact factors

Long-established citation gaming practices, such as citing papers in the journal to which the article is submitted are prevalent, but not highly so. On the other hand, citing non-peer review sources, such as the social media, is seen as not an acceptable practice. As one focus group participant in the Chinese study (Nicholas et al. 2016) mentioned it would be like citing a conversation in a bar. However, citing open access publications is not thought to be an issue.

In terms of publishing, overall there are no big surprises here, with traditional values and practices tending to hold sway. Thus, relevance to the field is not surprisingly the most important factor when choosing where to publish research. One of the oldest trust markers, indexed by a reputable indexing service, was next most important. The fact that an outlet is open access counts the least for researchers. Another sign of the importance to the researchers of trust proxies in determining where to publish was the fact that they placed the criteria of being highly cited above peer reviewed. Possibly the biggest surprise was that a high percentage of these researchers said they were heavily or somewhat influenced by research policy directives or mandates. Less surprisingly they were directed most to publish in international journals with high impact factors. There is no great enthusiasm, nor negativity for that matter, evidenced towards open access publishing.

Malaysian researchers were not sure or unanimous about what the changes their fields had experienced over the past decade. They came closest to agreeing that their fields were experiencing increased pressure to publish and, thus, there is a flood of mediocre/poor quality. Chinese researchers on the other hand were more inclined to believe the biggest change was that greater collaboration and sharing was making it easier to determine the trustworthiness of scholarly content, like their international counterparts.

This study provides us with some detailed information about how Malaysian and Chinese researchers assess trustworthiness and quality and in regard to their scholarly reading, citing 
and publishing and how they perceive changes in trust in the light of the emergence of new forms of scholarly communication. The results are tentative and exploratory, and our findings here should be interpreted in the context of the international evidence of previous studies (Jamali et al. 2014).

As with any survey research, a limitation is that people report on what they claim they do. The survey was sent to researchers who had published at least one article in a traditional scholarly journal at some point in their careers and were on one of the publishers' mailing list. Therefore, the results do not represent scholars who have completely eschewed traditional publishing routes. For better understanding the difference between Malaysian and Chinese researchers in scholarly communication, qualitative approaches must be used to study why they behave differently in citing, reading and disseminating in future works. Future research may explore why social media is not a dominant trustworthy source of scholarly communication. If researchers worldwide are engaged in social media, why do researchers prefer traditional sources? If the current study's finding suggests that people report there is no difference in credibility among various scholarly information, why is the information not being shared in higher volumes on social media? As both Malaysian and Chinese research assessment do not yet recognise scholarly outputs on social media, careers will continue to depend on formal, peer-reviewed publications. Follow up research should track changes, if any, in researchers' perception of social media sources' credibility.

\section{ACKNOWLEDGEMENT}

We sincerely thank all the research participants for their precious time and valuable insights. We acknowledge funding received from the Ministry of Higher Education Malaysia (HIRMOHE) UM.C/HIR/MOHE/FCSIT/11) and China National Social Science Fund (No.15CTQ026) which made it possible to undertake this research.

\section{REFERENCES}

Abramo, G., D'Angelo, C.A. and Di Costa, F. 2010. Citations versus journal impact factor as proxy of quality: could the latter ever be preferable? Scientometrics, Vol.84, no. 3: 821833.

Abrizah, A., Zainab, A.N., Edzan, N.N. and Koh, A.P. 2013. Citation performance of Malaysian scholarly journals in the Web of Science, 2006-2010. Serials Review, Vol. 39, no. 1: 4755.

Abrizah, A., Badawi, F., Zoohorian-Fooladi, N., Nicholas, D., Jamali, H. and Norliya, A.K. 2015. Trust and authority in the periphery of world scholarly communication: A Malaysian focus group study. Malaysian Journal of Library \& Information Science, Vol. 20, no. 2: 6783.

Abrizah, A., Nicholas, D., Noorhidawati, A., Aspura, M.K.Y.I and Badawi, F. 2016. Not so different after all: Malaysian researchers cross-discipline view of quality and trustworthiness in citation practices. Learned Publishing, Vol. 29, no. 3: 165-173.

Adams, J., King, C., and Ma, N. 2009. Global Research Report-China: Research and collaboration in the new geography of science. Leeds, UK: Evidence Ltd, Thomson Reuters. Available at: http://sciencewatch.com/sites/sw/files/sw-article/media/grrchina-nov09.pdf.

Ahlgre, P. and Waltman, L. 2014. The correlation between citation-based and expert-based assessments of publication channels: SNIP and SJR vs. Norwegian quality assessments. Journal of Informatics, Vol.8, no.4: 985-996. 
Allen, N. and Heath, O. 2013. Reputations and research quality in British political science: The importance of journal and publisher rankings in the 2008 RAE. British Journal of Politics \& International Relations, Vol. 15, no.1: 147-162.

Ameen K. 2017. Practices of quality and trustworthiness in scholarly communication: A case from Pakistan. Learned Publishing, Vol. 30, no.2: 133-142.

Antelman, K. 2004. Do open-access articles have a greater research impact? College \& Research Libraries, Vol. 65, no.5: 372-382.

Beall, J. 2016. Predatory journals: Ban predators from the scientific record. Nature, Vol. 534, no. 7607: 326.

Becher T. and Trower P. 2001. Academic tribes and territories: Intellectual inquiry and the cultures of disciplines. Milton Keynes: SRHE and Open University Press.

Bodaghi, N.B., Sanni, S.A. and Zainab, A.N. 2015. In competition with ISI: the perceptions of chief editors of Malaysian local journals. Learned Publishing, Vol. 28: 25-260.

Borgman, C.L. 2007. Scholarship in the digital age: Information, infrastructure, and the Internet. Cambridge, Mass.: MIT Press.

Bornmann, L. 2011. Scientific peer review. Annual Review of Information Science \& Technology, Vol. 45, no. 1: 197-245.

Bornmann, L., and Daniel, H. D. 2008. What do citation counts measure? A review of studies on citing behavior. Journal of Documentation, Vol. 64, no. 1: 45-80.

Bound, K., Saunders, T., Wilsdon, J., and Adams, J. 2013. China's absorptive state: Research, innovation and the prospects for China-UK collaboration. London, England: Nesta.

Cronin, B. 1984. The citation process: The role and significance of citations in scientific communication. Oxford, UK: Taylor Graham.

Cronin, B. 2001. Bibliometrics and beyond: Some thoughts on web-based citation analysis. Journal of Information Science, Vol. 27, no. 1: 1-7.

Evans, J. 2008. Electronic publication makes science and scholarship more narrow. Science, Vol. 321, no. 5887: 395-399.

Eyre-Walker, A. and Stoletzki, N. 2013. The assessment of science: The relative merits of postpublication review, the impact factor, and the number of citations. PLOS Biology, Vol.11, no.10.

Frandsen, T. F. 2009. Attracted to open access journals: a bibliometric author analysis in the field of biology. Journal of Documentation, Vol. 65, no. 1: 58-82.

Garfield, E. 1986. Do Nobel Prize winners write citation classics? Current Comments, No 23: 182-187.

Gravetter, F. J., and Forzano, L. B. 2009. Research methods for the behavioral sciences (3rd ed.). Belmont, CA: Wadsworth.

Haddawy, P., Saeed-UI Hassan; Asghar, A. and Amin, S. 2016. A comprehensive examination of the relation of three citation-based journal metrics to expert judgment of journal quality. Journal of Informetrics, Vol. 10, no,1: 162-173.

Harnad, S. 1999. The invisible hand of peer review. Exploit Interactive, No. 5. Available at http://www.exploit-lib.org/issue5/peer-review/.

Harnad, S., and Brody, T. 2004. Comparing the impact of open access (OA) vs. non-OA articles in the same journals. D-Lib Magazine, Vol. 10, no. 6: available at: http://www.dlib.org/dlib/june04/harnad/06harnad.html.

Jamali, H. R., Nicholas, D., Watkinson, A., Herman, E., Tenopir, C., Levine, K., Allard, S., Christian, L., Volentine, R., Reid Boehm, R. and Nichols, F. 2014. How scholars implement trust in their reading, citing and publishing activities: Geographical differences. Library \& Information Science Research, Vol. 36, no. 3: 192-202.

Kling, R. 2004. The Internet and unrefered scholarly publishing. In: Cronin, B. (Ed.), Annual Review of Information Science and Technology (ARIST), 38, Medford, NJ: ASIS\&T, 591631. 
Kling, R., Spector, L. and McKim, G. 2002. Locally controlled scholarly publishing via the internet: The Guild model. Proceedings of the American Society of Information Science \& Technology, Vol. 39, no. 1: 228-238.

Kousha, K. and Thelwall, M. 2014. Disseminating research with web CV hyperlinks. Journal of the Association for Information Science and Technology, Vol. 65, no. 8: 1615-1626.

Kurata, K., Mine, S., Morioka, T., Sakai, Y., Kato, S. and Ueda, S. 2009. Reading and Information seeking behavior of Japanese medical researchers in the era of the electronic journal and open access. Library and Information Science, No. 61: 59-90.

Kurtz, M.J., Eichhorn, G., Accomazzi, A., Grant, C.S., Demieitner, M., Henneken, E.A. and Murray, S.S. 2005. The effect of use and access on citations,. Information Processing \& Management, Vol. 41, no. 6: 1395-1402.

Malaysia, Ministry of Education. 2015. Malaysia education blueprint 2015-2025 (Higher education): Executive summary. Available at: http://hes.moe.gov.my/event/ docs/4.\%20Executive\%20Summary\%20PPPM\%202015-2025.pdf.

Mas Bleda, A., Thelwall, M., Kousha, K., and Aguillo, I. 2014. Successful researchers publicizing research online: An outlink analysis of European highly cited scientists' personal websites. Journal of Documentation, Vol. 70, no. 1: 148-172.

Mohammadi, E., Thelwall, M., Haustein, S., and Larivière, V. 2015. Who reads research articles? An altmetrics analysis of Mendeley user categories.Journal of the Association for Information Science and Technology. Vol. 66, no. 9: 1832-1846.

National Science Board. 2016. Science \& engineering indicators 2016: R\&D performance. Available at: https://www.nsf.gov/statistics/2016/nsb20161/\#/report/overview/ science-and-technology-in-the-world-economy/r-d-performance.

Nature Publishing Group. 2015. Turning point: Chinese science in transition. Available at: http://www.nature.com/press_releases/turning_point.pdf.

Nentwich M. 2005. Quality control in academic publishing: challenges in the age of cyberscience. Poiesis \& Praxis: International Journal of Technology Assessment and Ethics of Science, Vol. 3, no. 3: 181-198.

Nicholas, D. and Rowlands, I. 2011. Social media use in the research workflow. Information Services and Use, Vol. 31, no. 1-2: 61-83.

Nicholas, D., Watkinson, A., Volentine, R., Allard, S., Levine, K., Tenopir, C. and Herman, E. 2014. Trust and authority in scholarly communications in the light of the digital transition: Setting the scene for a major study. Learned Publishing, Vol. 27, no.2: 121124.

Nicholas, D., Watkinson, A., Hamid R. J., Eti H., Tenopir C., Volentine R., Allard S. and Levine K. 2015a. Peer-review: Still King in the digital age. Learned Publishing, Vol.28, no.1:1521.

Nicholas, D., Hamid R. Jamali, Anthony Watkinson, Eti Herman, Carol Tenopir, Rachel Volentine, Suzie Allard, and Levine, K. 2015b. Do younger researchers assess trustworthiness differently when deciding what to read and cite and where to publish? International Journal of Knowledge Content Development \& Technology Vol.5, No.2, 4563

Nicholas, D., Xu, J. Xu, L., Su, J. and Watkinson, A. 2016. Chinese researchers, scholarly communication behavior and trust. Learned Publishing, Vol. 29, 31-38.

Patel, J., Pierce, M., Boughton, S.L. and Baldeweg, S.E. 2017. Do peer review models affect clinicians' trust in journals? A survey of junior doctors. Research integrity and peer review, Vol. 2, no. 11. Available at: https://researchintegrityjournal.biomedcentral.com/ articles/10.1186/s41073-017-0029-8

Ponte, D. and Simon, J. 2011. Scholarly Communication 2.0: Exploring researchers' opinions on Web 2.0 for scientific knowledge creation, evaluation and dissemination. Serials Review, Vol. 37, no. 3: 149-156. 
Priem, J. and Hemminger, B.H. 2010. Scientometrics 2.0: Toward new metrics of scholarly impact on the social Web. First Monday 15. Available: http://firstmonday.org/htbin/cgiwrap/ bin/ojs/index.php/fm/article/view/2874/2570.

Research Information Network. 2009. Communicating knowledge: How and why UK researchers publish and disseminate their findings. A Research Information Network Report. Available at: http://www.rin.ac.uk/system/files/attachments/Communicatingknowledge-report.pdf.

Ronellenfitsch, U; Klinger, C; Buhr, HJ and Post, S. 2015. Reading behavior and preferences regarding subscriptions to scientific journals. Results of a survey of members of the German Society for General and Visceral Surgery. CHIRURG, Vol. 86, no. 11: 1051-1058.

Rowland, F. 2002. The peer review process. Learned Publishing, Vol. 15, no. 4: 247-258.

Rowlands I, Nicholas D, Russell B, Canty N, and Watkinson A. 2011. Social media use in the research workflow. Learned Publishing, Vol. 24, no. 3: 183-195

Rusch-Feja, D. and Siebeky, U. 1999. Evaluation of usage and acceptance of electronic journal. D-Lib Magazine, Vol. 5, no. 10. Available at: http://www.dlib.org/dlib/ october99/rusch-feja/10rusch-feja-full-report.html.

Shema, H., Bar-llan, J., and Thelwall, M. 2014. Do blog citations correlate with a higher number of future citations? Research blogs as a potential source for alternative metrics. Journal of the Association for Information Science and Technology, Vol. 65, no. 5: 10181027.

Simpson, A. H. R. W. 2015. Orthopaedic journals, impact factors, research impact and research quality. Bone \& Joint Research, Vol.4, no.7: 117-119.

Taylor, M. and Kamalski, J. 2012. The Changing Face of Journal Metrics. Elsevier Connect. Posted on 28 November 2012. Available at: http://elsevierconnect.com/the-changingface-of-journal-metrics/.

Tenopir, C. 2003. Use and users of electronic library resources: an overview and analysis of recent research studies. Report for the Council on Library and Information Resources, August 2003. Available from http://www.clir.org/pubs/reports/pub120/pub120.pdf.

Tenopir, C., King, D. W., Edwards, S., and Wu, L. 2009. Electronic journals and changes in scholarly article seeking and reading patterns. Aslib Proceedings, Vol. 6, no. 1: 5-32.

Tenopir, C, Allard, S., Bates, B., Levine, K., King, D.W., Birch, B., Mays, R., \& Caldwell, C. 2010. Research publication characteristics and their relative values: A report for the Publishing Research Consortium. Available from http://www.publishingresearch.net/.

Tenopir, C, Allard, S., Bates, B., Levine, K., King, D.W., Birch, B., Mays, R., and Caldwell, C. 2011. Perceived Value of Scholarly Articles. Learned Publishing, Vol.24, 123-132.

Tenopir, C., Allard, S., Levine, K., Volentine, R., Christian, L., Boehm, R., Nichols, F. Christensen, R., Nicholas, D., Watkinson, A., Jamali, H.R., Herman, E. and Thornley, C. 2013. CIBER's trust and authority in scholarly communications in the light of digital transition: Final report. University of Tennessee USA and CIBER Research Ltd UK.

Tenopir C., Levine K., Allard S., Christian L., Volentine R., Boehm R., Nichols F., Nicholas D., Jamali Hamid R., Herman E., Watkinson A. 2015. Trust and authority of scholarly information in a digital age: results of an international questionnaire. Journal of the Association for Information Science and Technology. Vol. 67, no. 10: 2344-2361.

Thelwall, M. and Kousha, K. 2015. ResearchGate: Disseminating, communicating and measuring scholarship? Journal of the Association for Information Science and Technology. Vol. 66, no. 5: 876-889.

Vakkari, P. 2008. Perceived influence of the use of electronic information resources on scholarly work and publication productivity. Journal of the American Society for Information Science and Technology, Vol. 59, no.4: 602-612. 
Von Elm, E., Wandel, S., and Jueni, P. 2009. The role of correspondence sections in postpublication peer review: A bibliometric study of general and internal medicine journals. Scientometrics, Vol. 81, no. 3:747-755.

Warlick, S.E. and Vaughan, K.T.L. 2007. Factors influencing publication choice: Why faculty choose open access. Biomedical Digital Libraries, Vol. 4, no. 1.doi: 10.1186/1742-55814-1.

Watkinson, A., Nicholas, D., Thornley, C., Herman, E., Jamali, H.R., Volentine, R., Allard, S., Levine, K. and Tenopir, C. 2016. Changes in the digital scholarly environment and issues of trust: An exploratory, qualitative analysis. Information Processing \& Management, Vol. 52, no. 3: 446-458.

Weller, A. C. 2001. Editorial peer review: Its strengths and weaknesses. Medford, NJ: Information Today, Inc.

Wicherts, J.M. 2016. Peer review quality and transparency of the peer-review process in open access and subscription journals. PLOS One, Vol. 11, no. 1: e0147913.

$\mathrm{Xu}$, J., Nicholas, D., Zeng, Y. and Su, J. 2016 Are open access journals trusted by Chinese scholars. Geomatics and Information Science of Wuhan University. Vol.41, no.5:130-136

Zuccala, AA, Verleysen, FT; Cornacchia, R, and Engels, TCE. 2015. Altmetrics for the humanities Comparing Goodreads reader ratings with citations to history books. ASLIB, Journal of Information Management, Vol. 67, no. 3: 320-336. 